\title{
SOB AS VESTES DE SERTÃO VEREDAS, O GERAIS. A RESISTENNCIA COTIDIANA NO SERTÃO DO IBAMA*
}

Carmen Silvia Andriolli

\section{Introdução}

Minha intenção neste artigo é refletir sobre a dinâmica da relação entre o vaqueiro Samuel Borges dos Santos e os gestores do Parque Nacional Grande Sertão Veredas no que tange ao uso da terra.

O parque nacional foi criado em 1989 no noroeste de Minas Gerais e ampliado para o sudoeste da Bahia em 2004. Anteriormente, essa área era composta por fazendas de criação de gado, pequenas propriedades rurais e terras devolutas. Com a criação do parque nacional, atividades que outrora eram permitidas foram interditadas. A área, por se tratar de uma unidade de conservação de proteção integral, é destinada à preservação ambiental, ao turismo e à realização de pesquisas científicas; o uso da terra para atividades agropecuárias, bem como a residência de populações humanas não são admitidos. ${ }^{1}$ De acordo com a legislação que rege as unidades de conservação, uma indenização pela terra e pelas benfeitorias é paga àqueles que possuem terra escriturada. Os que possuem título de posse recebem somente pelas benfeitorias.

Nesse cenário, meu objetivo é elucidar que o vaqueiro Samuel transportava o modelo de relação que desenvolvera com seu ex-patrão para sua relação com os gestores do parque enquanto esperava pela indenização de sua propriedade. Como forma de resistência, a resistência miúda de não enfrentar, o vaqueiro agiu desta forma durante 21 anos para se manter junto a terra, a despeito da legislação ambiental.

Nos livros The weapons of the weak (1985) e Domination and the arts of resistance (1990), James C. Scott, ao analisar as relações de classe no cotidiano entre ricos e pobres de uma aldeia malaia, trouxe à tona uma forma de resistência: a resistência de pequena escala realizada normalmente sem uma organização formal ou líderes oficiais, no que tange à apropriação do trabalho 
e das produções, sobretudo de camponeses. Essa resistência incluía furtos de arroz, debulhada incompleta para que outros membros da família colhessem os grãos, matança dos animais dos ricos que invadiam as hortas, difamações e boatos. Nomeada "arma dos fracos" por James C. Scott, essa resistência cotidiana impõe barreiras, frustra as ambições dos ricos, bem como molda, a longo prazo, as formas de dominação igualmente ou até mais do que as rebeliões e greves, que são muito arriscadas por poderem terminar em repressão.

A partir dos dados etnográficos registrados por mim no noroeste de $\mathrm{Mi}$ nas Gerais, compreendi que a relação entre o vaqueiro Samuel e os gestores do parque estruturava-se consoante a lógica que operava no pensamento do vaqueiro e que variava através do tempo, do lugar e, sobretudo, das distribuições de poderes (Bourdieu 1996 [1994]). ${ }^{2}$ Tal lógica tinha como esteio a forma como Samuel se relacionava enquanto vaqueiro com seu ex-patrão. Enredadas a essa transferência estavam as ambiguidades que perpassavam a relação de outrora, como o leitor verá adiante. Ressalto entretanto que, diferentemente de Bourdieu (1996 [1994]), estou tratando o habitus de vaqueiro como "arma dos fracos" de Samuel no novo contexto (Scott 1985, 1990).

O vaqueiro Samuel é o protagonista desta etnografia por ser figura emblemática das transformações ocorridas no que tange ao uso da terra: num primeiro momento, como agregado de uma fazenda pecuarista, posteriormente, proprietário de terra e, por fim, morador de parque. A etnografia contemplou tanto minhas observações diretas sobre o tempo presente quanto a memória do vaqueiro sobre o tempo passado.

Samu, como é conhecido na região, como narrador, sabia trocar experiências vividas, que possuíam muito valor, por palavras, invocando aqui Walter Benjamin. Por meio da narrativa, o vaqueiro falava-me de sua experiência, não me contava informações; tinha a habilidade de narrar; relatava sua experiência, sua história, sem dar explicações. Em sua narração, ditos, não ditos, entreditos e silêncios estavam presentes. Como Lescov, narrador apresentado por Walter Benjamin, Samu relatava 'histórias velhas que o povo contava' - como a da 'Onça mais o Marruá' — ou como foi a 'chegada do parque' ${ }^{3}$ e como isso tornou a 'vida parada'. Narrava com a precisão de um tiro certeiro. No entanto, o que estava nas entrelinhas da estória, os não ditos, os entreditos, os silêncios, o ouvinte deveria interpretar (Benjamim 1996 [1975]:67). Ao narrar 'dizeres dos antigos', relatos sobre o tempo 'de primeiro', 'causos' acontecidos, Samu estruturava sua narrativa por meio de interpretações que advinham do que acontecia no presente.

O modo de vida do tempo de 'primeiro' estava timidamente ao alcance dos olhos e era referenciado por Samu a partir da categoria nativa 'Gerais'. Este estava sendo revestido pelo 'Sertão', pelo tempo do 'viver apertado'. 
Dito de outro modo, as transformações sobre o uso da terra revelavam tempos (tempo 'de primeiro' e tempo do 'viver apertado') que remetiam a uma morfologia social referenciada pelas categorias nativas 'Gerais'/'Sertão' ao ser analisada no processo social. Essa trama nos permite analisar a "forma material dos agrupamentos humanos" e como esta "afeta os diferentes modos da atividade coletiva" (Mauss 2003 [1950]:426).

As distintas formas de nomeação do tempo - tempo 'de primeiro' e tempo do 'viver apertado' — não diziam respeito a tempos diversos, mas sim a uma concepção específica de tempo que refletia determinadas atividades traduzidas nas categorias nativas 'Gerais'/'Sertão'. A análise do sentido local do termo tempo foi realizada por vários autores em diferentes universos empíricos.

Em Política e tempo: nota exploratória (2001), Moacir Palmeira analisa o que representa, entre populações camponesas do Nordeste brasileiro, o termo tempo em sua conjunção com outros termos, como política, greve, festas, sindicato, Arraes. Para o autor, nomear o tempo de uma ou de outra forma não diz respeito a uma concepção de tempo linear ou cíclica, cumulativa ou não cumulativa. As diferentes formas de nomeação nativa do tempo referem-se a "uma certa maneira de a população recortar/ representar a estrutura social" (Palmeira 2001:172). ${ }^{4}$ Por exemplo: 'tempo dos Carneiro' ou tempo do 'viver apertado', para retomar tão somente estas duas formas de nomeação encontradas no nosso universo empírico, é a maneira como o vaqueiro Samu representa o 'Gerais' ou o 'Sertão' no que tange às atividades que podiam ser realizadas. Em outras palavras, em diálogo com as reflexões de Palmeira (2001), o termo tempo para o vaqueiro não se refere à temporalidade, mas sim a um recorte da estrutura social que pressupõe um regime específico de atividades para o espaço-tempo em questão. Como o leitor verá nas próximas seções deste artigo, as acepções nativas de tempo - 'tempo dos Carneiro', da 'liberdade', tempo do 'viver apertado', do 'viver do compra' ou de 'ter que pedir permissão' — se mostravam imbricadas e elucidavam as transformações sobre o uso da terra que faziam do 'Gerais' o 'Sertão'.

Nesse sentido, há uma relação espaço-tempo acionada pelo vaqueiro a partir das categorias nativas 'Gerais'/ 'Sertão', 'tempo dos Carneiro'/ tempo do 'viver apertado'. ${ }^{5} \mathrm{O}$ modo de vida que me era comunicado correspondia à organização da situação atual, a partir de uma ótica do passado. Ou seja, ao descortinar o 'Gerais', Samu revelava-me como ele reagia ao 'Sertão', na medida em que o vaqueiro fazia com que o cenário atual dialogasse com estruturas anteriores. ${ }^{6}$

O cruzamento dos tempos que foram revelados tanto pela minha observação direta quanto pela memória do narrador-personagem remetia a 
um modo de vida ordenado por uma moral camponesa, que estruturava as relações entre o vaqueiro e os demais personagens que compunham o 'Gerais'/ 'Sertão': vizinhos, família, patrão, gestores do parque nacional, seres não humanos. Essa moral camponesa estruturava, sobretudo, a relação do vaqueiro com a terra.

No artigo "'Com parente não se neguceia'. O campesinato como ordem moral" (1990 [1987]), Klaas Woortmann faz um esforço analítico para elaborar a noção de "ética camponesa", ${ }^{7}$ tomando como base de análise a etnografia brasileira do campesinato. O esforço do autor direciona-se para revelar que o campesinato pode ser compreendido para além da análise da sua lógica econômica, do seu modo de produção/reprodução, ao destacar a moralidade que é própria dele, definindo-o como uma ordem moral. Para tanto, apoia-se sobretudo na análise acerca do valor da terra para o camponês, a terra enquanto valor de uso e não como mercadoria. O que guia o autor nessa empreitada é a "campesinidade, entendida como uma qualidade presente em maior ou menor grau em distintos grupos específicos", ou seja, "uma campesinidade em graus distintos de articulação ambígua com a modernidade" (:13-14). A campesinidade como uma ética camponesa emerge, segundo o autor, da articulação entre as categorias terra, trabalho e família pelo fato de elas serem "nucleantes" e interdependentes. Ou seja, a terra é pensada em relação à família e ao trabalho, assim como o trabalho é pensado em relação a terra e à família. Tais categorias vinculam-se a valores e princípios da ética camponesa que orientam as questões do cotidiano das famílias camponesas, como também da sua sociabilidade com as demais unidades domésticas do seu meio.

Os dados etnográficos elucidam que essa moral camponesa que estruturava a relação do vaqueiro, sobretudo com a terra, foco de nossa análise, não significava que Samu tinha um apego a uma determinada terra em específico, como uma terra insubstituível, ${ }^{8}$ como pode sugerir a noção de ética camponesa de Klaas Woortmann (1990 [1987]). A meta do vaqueiro era ter uma terra, podendo ser esta ou outra, como parte das condições necessárias para viver como quando ali era o 'Gerais', fato que é compatível com vender e comprar terra, com mudar-se daqui para acolá. No entanto, isso não queria dizer que o vaqueiro percebia a terra como mercadoria. A terra, o trabalho e a família formavam-se mutuamente e elucidavam a moral camponesa que o vaqueiro carregava em sua algibeira, como mostrarei nas seções subsequentes.

Diante dessas considerações, informo que o artigo está dividido em duas seções. Na primeira, apresento como Samu narrou a vida quando ali era o 'Gerais', sobretudo no que tange ao uso da terra e à sua relação com o 
patrão. Darei especial atenção às especificidades do trabalho de vaqueiro, bem como ao significado da liberdade para esse trabalhador. Para além disso, elucidarei como Samu permaneceu utilizando a terra da forma como fazia anteriormente quando apenas os roçados foram proibidos pelo Ibama. Estas questões serão fundamentais para compreendermos o foco da seção seguinte: o 'Sertão' da 'lei do promotor' e a forma como Samu agiu para se manter junto a terra enquanto aguardava a indenização, chegando a ponto de esparramar seu gado. Por fim, farei algumas considerações finais.

\section{Entre 'Gerais' e 'Sertão'}

Como era a vida quando ali era o 'Gerais' no que tange ao uso da terra? Antes do parque nacional, a vida no 'Gerais', no 'tempo dos Carneiro', era regida por um sistema de direitos sobre a terra que se legitimava pelo uso direito de morar ou de criar — complementado pelo uso comum das áreas de chapadas, carrasco, vazantes e vargens. ${ }^{9}$ Àquela época, o que tinha valor econômico era o gado, não a terra. ${ }^{10}$ Dessa feita, o fazendeiro permitia pelo uso o direito a terra.

O 'ponto nosso', 'o local do trabalho nosso', 'ele tinha morada na beira dos Porcos e trabalhava nesse brejo lá', estas são expressões faladas por Samu e seus vizinhos, que revelavam o direito sobre a terra pelo uso que se fazia dela. Tal sistema, que se baseava no uso de um máximo de ambientes naturais, era composto por criar gado 'na solta' e por fazer roçados.

No 'tempo das águas', o gado era criado 'na solta' nas vargens e vazantes dos rios; no 'tempo da seca', era criado no 'Gerais' (áreas de uso comum). ${ }^{11}$ Os brejos - nas chamadas terras de cultura, que podiam ser de 'direito de morar', 'direito de criar' ou de propriedade - eram utilizados para os roçados. Nessas áreas, a família de Samu plantava arroz, feijão e milho. Plantavam durante dois anos no mesmo local. Quando viam que a terra 'queria fraquear', 'largavam' e iam para outro lugar.

No 'tempo dos Carneiro' havia, portanto, uma lógica local do direito sobre as terras já tituladas pertencentes, neste caso, à Família Carneiro, que seguia um código social, baseado em dois direitos: o 'direito de criar' dado aos vaqueiros e o 'direito de morar' concedido aos demais agregados. Em outras palavras, havia um sistema de uso e ocupação da terra da Família Carneiro que se estruturava pela utilização combinada das áreas de uso comum, não cercadas, com o das áreas de direitos (de criar e morar); estas últimas se legitimavam pelo uso das unidades domésticas. ${ }^{12}$ Havia, portanto, uma solidariedade esperada entre patrão e agregado, bem como a coexis- 
tência dos modelos de reprodução camponesa e de reprodução das grandes propriedades, ambos interligados. ${ }^{13}$ No entanto, o leitor verá adiante que a relação entre patrão e agregado muitas vezes era perpassada por conflitos.

$\mathrm{O}$ 'direito de criar' concedido aos vaqueiros incluía, além da morada e do roçado, a permissão para criar seu gado embolado com o gado do patrão e nas terras deste. Trabalho árduo, madrugadas no campo compunham as características do vaqueiro sertanejo. "De quatro crias cabia-lhe uma; podia assim fundar fazenda por sua conta" (Capistrano de Abreu s/d). 'Gado tirado na sorte' é como Samu nomeava o pagamento que recebia, isto é, $25 \%$ das crias do rebanho do patrão. Era assim no 'tempo dos Carneiro'. Pagamento em dinheiro não havia.

Em troca do 'direito de criar' concedido pelo patrão, o vaqueiro deveria estar à disposição da fazenda todo o tempo, campeando gado, trabalhando na ordenha ou amansando animais de montaria. Um "código costumeiro do uso da terra e do trabalho" era firmado verbalmente entre o fazendeiro e o vaqueiro; tal código compunha-se de deveres a serem cumpridos pelo vaqueiro mediante uma "ordem verbal" do que se podia fazer a cada dia ou a cada época (Moura 1988). Esse código costumeiro tinha como principal característica o compromisso assumido, fato que supunha ter o vaqueiro uma qualidade de devedor.

Samu foi fiel e leal à ordem social da fazenda e assim adquiriu o 'direito de criar'. Como vaqueiro, Samu cuidava do gado da Família Carneiro, que morava em Januária. Vaqueiros habilidosos e confiáveis eram necessários para cuidar de gado solto em terras indivisas. A palavra do vaqueiro para o patrão não podia expressar dúvida. O gado era o maior bem monetário em terras em que a agricultura era gênero menor. Além disso, eram os vaqueiros que negociavam com o boiadeiro a venda das reses. A confiança da Família Carneiro no trabalho do vaqueiro era imprescindível. Já dizia sêo Major, personagem do conto "O burrinho pedrês", de Guimarães Rosa, o prestígio que o vaqueiro tinha para o seu patrão. "Escuta: eu dou valor aos meus vaqueiros, e o que eles contam de si eu aprecio. Pessoal meu é gente escolhida..." (Rosa 2001:68). ${ }^{14}$

Com o pagamento pelo trabalho de vaqueiro 'tirado na sorte', além da venda dos mantimentos que produzia nos roçados, Samu comprou 75 hectares da antiga Fazenda Mato Grande. A despeito de adquirir sua terra, continuou a trabalhar e a morar na fazenda do patrão. Hermínio, seu irmão mais velho, comprou outros 75 hectares de terra ao lado da terra comprada por Samu. Uma única escritura foi feita para os 150 hectares, por sugestão da filha do vendedor das terras, 'finado Plácido', porque gastariam menos dinheiro com a documentação. Hermínio e tampouco Samu recusaram a sugestão. — "Somos todos irmãos mesmo" — concluiu Samu. 
Sendo proprietário de terra porque antes era vaqueiro e recebia 'gado tirado na sorte', Samu distinguia-se dos demais agregados. Ser vaqueiro, manejar um objeto que é antes um ser vivo e que em si é como remuneração, traz à tona uma relação específica contida no trabalho de vaqueiro (Galvão 1972). Por um lado, o vínculo estreito - físico e afetivo - com o gado; por outro, 'mexer com criação' e receber por esse trabalho - o 'gado tirado na sorte' - possibilitavam ao vaqueiro passar de empregado a dono de gado e de terra; podia, nesse momento, conceder 'pouso', 'de-comer' ou terra para ser roçada, como fizera com o 'povo do Cajueiro', que plantava, roçava e colhia, ao passo que Samu 'dava' o feijão catador e a terra.

Ter terra, ter gado, ter animal para 'andar montado', proporcionando a Samu passar de empregado a dono, imprimiam nele uma qualificação social em relação aos demais moradores da fazenda. Ter animal para 'andar montado' conferia a Samu, sobremaneira, sensação de liberdade, ${ }^{15}$ tanto por não se limitar ao trabalho no cabo da enxada quanto por fisicamente 'rodar o mundo no lombo do cavalo'.

A confiança da Família Carneiro proporcionou a Samu, enquanto vaqueiro leal, o 'direito de criar', como dito anteriormente. Para além disso, sua lealdade ao patrão facultou-lhe privilégios, como a prorrogação do 'direito de criar' como condição colocada pelos patrões para o futuro comprador das fazendas da Família Carneiro: o Doutor Luciano. Era a condição que seus patrões impunham ao novo proprietário para a venda da terra se concretizar. Samu pôde, assim, continuar com o 'direito de criar', isto é, criar seu gado 'na solta' nas terras dos ex-patrões. Ali continuava a ser o 'Gerais' do 'tempo dos Carneiro'.

A despeito disso, o vaqueiro não era um trabalhador que aceitava de cabeça baixa os mandos do patrão por saber que privilégios poderia ter devido à confiança que lhe era outorgada. Ele aprendera a negociar; aprendera a valorizar sua presença. Sabia de sua importância na lida do campo. Este fato fica claro nas falas de Samu sobre quando o parque chegou 'da primeirinha vez'. Samu já não trabalhava mais para a Família Carneiro, mas deixou sua terra para voltar a 'trabalhar na Carinhanha pro Zezé Carneiro'. Seu filho Santo foi quem permaneceu cuidando da propriedade da família. Com a 'lei do Ibama chegando', Santo falou ao pai para retornar com medo de perderem a terra pelo fato de o dono nela não estar. Samu não queria deixar o trabalho na Carinhanha, porque estava ganhando seus bezerrinhos. Por insistência do filho, Samu retornou. Arrependeu-se, pois se tivesse continuado a trabalhar para Zezé Carneiro, a despeito da 'chegada do parque', teria formado um rebanho maior e teria condições para alicerçar um chão fora dali; não precisaria estar à espera da indenização ${ }^{16}$ para poder comprar outra terra. 
Esse era o cálculo que o vaqueiro fazia. Mas um retorno ao momento em que Samu deixou o trabalho se faz necessário nesta parte do texto.

Com sua saída, a família Carneiro contratou Valdo, outro filho de Samu - "porque ele sabia dividir o gado e o vaqueiro que estava lá não sabia. Eram muitos irmãos" - falou-me Samu ao explicar que seu filho o ajudava no trabalho como vaqueiro no 'tempo dos Carneiro'. Após anos de trabalho de Valdo, a família Carneiro pediu que ele deixasse a lida. - "Acho que era medo, porque já tinha muitos anos". Os patrões sabiam que se Valdo encaminhasse alguma questão para a Justiça, certamente ganharia, na medida em que não era possível o fazendeiro argumentar que o vaqueiro não era seu empregado. Entre o trabalho no campo, na ordenha e na domação de animais de montaria, o vaqueiro trabalhava 30 dias por mês. Samu não expressou indignação com este fato, mas com outro que estava por contar: - "Quando estavam atrás dele, foram buscar ele. Agora para pagar, eles queriam que ele fosse buscar". Samu falou para a Família Carneiro levar o pagamento para Valdo. Nesse momento ficava clara a autonomia moral do vaqueiro perante o patrão. Havia enfrentamento baseado no respeito recíproco existente na relação vaqueiro-patrão.

A valorização do vaqueiro perante seu patrão encerrava-se no fato de esse trabalhador cuidar, com lealdade, do bem mais precioso da fazenda. ${ }^{17}$ A partir do trabalho especializado, o vaqueiro acumulava gado e, numa progressão temporal, o vaqueiro leal passava à condição de proprietário de gado e de terra, como explicitou Samu quando narrou que deixou o trabalho de vaqueiro por já ter alicerçado um chão. Do ponto de vista econômico, sua própria posição financeira de vaqueiro era contígua à do patrão. Seu lugar na relação patrão-vaqueiro, portanto, não era estático. ${ }^{18}$

O vaqueiro, muito embora agregado, diferenciava-se, assim, daquele agregado que trabalhava a terra, pois além de acumular bens, não tinha seu trabalho vinculado ao cabo da enxada. O fato de campear gado ao invés de trabalhar preso a terra proporcionava ao vaqueiro uma sensação de liberdade. Sentia-se sobretudo independente do patrão por se tornar dono de bens, por poder acumular. Para além disso, ao contrário das peias existentes na relação entre patrão e agregado (Franco 1997), a relação entre patrão e vaqueiro era atravessada pela ambiguidade; o vaqueiro era fiel, respeitava a ordem social da fazenda, não travava um conflito direto com o patrão e, ao longo do tempo, tornava-se dono de gado e terra. Em outras palavras, ao mesmo tempo em que se tornava independente, permanecia fiel - duas qualidades contraditórias. A ambiguidade estava, portanto, dada. ${ }^{19}$

O 'tempo dos Carneiro' vez ou outra foi apresentado por Samu com o descortino das relações de conflito entre agregado e patrão. O que dominou 
suas falas foi a reconstrução de um passado de 'liberdade' em detrimento de um presente que estava revestido de proibições, o que não significa que não existissem proibições no tempo 'de primeiro'. O 'tempo dos Carneiro' trouxe à luz o Gerais - o conhecido - com seus pastos sem fecho, quintais sem cerca e gado criado 'na solta'. Isto significava viver 'folgados'. No sertão, o sertão criado pelo Ibama, a vida trajava vestes apertadas.

Nesse 'Sertão' como vestes apertadas, Samu continuou a exercer o 'direito de criar' conquistado no 'tempo dos Carneiros'. Como faziam Samu e seu filho Valdo no 'tempo de primeiro', o vaqueiro e o sobrinho Zezão ${ }^{20}$ criavam juntos os gados de irmãos, sobrinhos, primos, netos e cunhados. O rebanho familiar, criado principalmente para corte, totalizava 800 reses. Solto nas vargens das propriedades de Samu e Hermínio, pai de Zezão, o gado 'batia mais' nas áreas de vargens dessas propriedades, assim como nas vazantes do rio Preto e do rio Carinhanha. A última área pertencia à família dos Carneiro, ex-patrões de Samu e Hermínio, áreas concedidas ao uso dos vaqueiros por meio do 'direito de criar'.

Mas como Samu continuava a exercer o 'direito de criar' adquirido no 'tempo dos Carneiro' diante das proibições sobre o uso da terra colocadas pelo Ibama? Roçados ele já deixara de fazer. Mantinha pasto formado? Ateava fogo para renovar o pasto?

Pasto formado e cercado o vaqueiro teve até 2007. Eram 20 hectares usados em momentos de precisão, isto é, quando no 'tempo das águas' as vargens e vazantes estavam muito cheias e o gado por ali não poderia 'bater', senão atolaria. Ou usados 'na seca', quando o capim da vargem estava 'fraco'. A gestora à época proibiu Samu de atear fogo para renovar o pasto. Para não ter 'desprazer', Samu cumpriu a lei, e o pasto atualmente — 'tem pauzão grosso. Se pudesse roçar, estaria folgado'. 'Estaria folgado' porque no entender de Samu só é possível criar gado preso, isto é fora das áreas de vargens e vazantes e assim atender, neste momento, à outra lei - a 'lei do promotor' - se tivesse 'espaço', isto é, pasto formado. Mas sobre esta lei falarei mais adiante. O que quero ressaltar é que o vaqueiro conseguia manter o 'direito de criar' atendendo à ordem do Ibama de não atear fogo, sendo, por conseguinte, leal ao 'povo do Ibama'.

Outro exemplo que revela tanto a obediência às leis do Ibama como a lealdade ao órgão governamental refere-se ao momento em que Samu precisou de 'paus' para refazer sua casa que tinha sido queimada. O vaqueiro primeiramente pediu 'ordem' para o Ibama se poderia 'tirar alguns paus'. A gestora à época aprovou, desde que Samu não tirasse as madeiras de um só local, para não configurar um desmate. — "Disse para não tirar embolado". Samu acatou a ordem, embora soubesse de um lugar com ótimos 'paus 
todos juntinhos'. Poderia ter resolvido seu problema ali mesmo, mas como 'temos que atender ordem' não o fez. - "Peguei um [moço] para descascar a madeira. Quando veio um carro, ele correu. Viram e perguntaram onde tirei. Eu ensinei. Pois foram lá ver! Foram lá, olharam e eu ganhei vantagem! Agora se eu tivesse metido o machado, eu tinha sido multado!". O vaqueiro ressaltou, sobretudo, que no mês seguinte ao acontecido comparecera ao escritório do Ibama, e que a gestora fez questão de dizer que da forma como Samu tinha extraído a madeira estava correto. Com isso, Samu continuou a manter a confiança do 'povo do Ibama', que de tempos em tempos mudava, ora era homem, ora era mulher.

As situações narradas por Samu — não atear fogo para renovar o pasto, bem como pedir 'paus' para reconstruir sua casa respeitando as leis do Ibama, tanto no solicitar autorização quanto na extração da madeira - revelam a forma que ele encontrou para ter aval para realizar atividades que antes da chegada do parque podia desempenhar. O intuito do vaqueiro era expressar, para além de uma cordialidade no relacionamento com os gestores - a mesma cordialidade que dedicava à sua relação com o ex-patrão — que não desacatara as ordens do Ibama. Neste cenário, o vaqueiro conseguia manter o 'direito de criar' adquirido no 'tempo dos Carneiro'. Samu dizia que não podia reclamar do órgão, porque sempre que necessitou de autorização para realizar uma ou outra atividade ele conseguira. Entre as situações narradas, o vaqueiro acionava um ditado de sua mãe para justificar sua conduta: — "Desengano das vistas é furar o olho".

As transformações no uso da terra centraram-se, num primeiro momento, na proibição dos roçados. Samu, por ser aposentado rural, assim como sua esposa, pôde acatar as 'ordens do Ibama' e deixar de fazê-los. Os vizinhos que moravam quando ali era o 'Gerais', por não serem aposentados e por serem posseiros, acataram a alternativa que lhes foi oferecida pelos gestores do parque: serem realocados para o Assentamento São Francisco no município de Formoso, MG. ${ }^{21}$ Os poucos que ficaram, caso dos vizinhos Raimundo e Róso, conseguiram permanecer por diferentes motivos.

Raimundo era proprietário de terra e afirmava para os gestores que só sairia quando recebesse a indenização. Não tinha sido vaqueiro ou agregado da Família Carneiro. Não tinha, portanto, o 'direito de criar'. Sua propriedade era cercada, e Raimundo possuía menos reses que Samu. Criava seu gado nos 120 hectares que compunham sua propriedade e, às vezes, soltava seu rebanho em áreas já indenizadas. Sua relação com o 'povo do Ibama' era permeada por conversas ríspidas, bem como pela presença da fiscalização em sua propriedade.

Róso, por sua vez, por ser posseiro em terras mineiras e não ter aceitado ser realocado no Assentamento São Francisco, aceitou 'tomar conta' da terra 
de Maria Espanhola, na área baiana do parque, e receber por esse trabalho um 'agrado'. Com a falta de periodicidade no pagamento, bem como com as proibições sobre o uso da terra que passaram a existir também na área baiana do parque, Róso, por ser sobrinho de Samu, criava gado 'na meia' com o vaqueiro. Tanto Róso como sua esposa, Maria Cardoso, reclamavam do 'povo do Ibama', no que tange às proibições sobre o uso da terra e no que se refere à lentidão do processo de indenização das benfeitorias.

Com a demora do pagamento, afirmavam que era um absurdo terem que parar de roçar. Ambos possuíam a declaração de posse da terra de seus pais, localizadas na área mineira do parque. No entanto, tanto a posse dos pais de um quanto a do outro foram abandonadas pelo casal no momento em que foram proibidos de fazer roçados. Com isso, as benfeitorias se deterioraram, fato que no olhar do casal dificultava o recebimento da indenização. Maria Cardoso afirmava: - "Eu tenho duas fotos de lá da minha casa. Das minhas coisas que eu tinha, do quintal, a plantação que eu tinha, eu tenho foto. Só não tenho foto da casa, porque tirou na frente. Aí não pegou a casa. A gente não sabia que a gente ia sair! Mas que tem da frente, da minha plantação de casa, eu tenho". Maria Cardoso tem fotos daquilo que foi tomado pela regeneração do cerrado.

Samu, mais velho e tomando como base sua autonomia moral, dava um conselho à sobrinha quando esta manifestava indignação com as atitudes do 'povo do Ibama': - "Quem precisa que corre atrás. Os outros não sabem o que estamos precisando". Mas outra interdição estava por vir e quebraria a reciprocidade esperada por parte do vaqueiro Samu na sua relação com o 'povo do Ibama'.

\section{A 'lei do promotor'}

Herculano, pequeno proprietário de terra e morador distante de Samu, criava gado 'na meia' com pessoas que não eram da família, e utilizava áreas que não faziam parte de sua propriedade, muitas vezes áreas já indenizadas ou de outros proprietários. Para o Ibama, essa conjuntura tinha um grau de abuso maior do que o de Samu, pois implicava comércio, diferentemente de criar gado 'na solta' em áreas que não estavam indenizadas e somente em família, como era o caso do vaqueiro.

O fato de Herculano criar gado 'na meia' com pessoas de fora da sua família em áreas para além dos limites de sua propriedade e em áreas indenizadas ocasionou algo trágico ao olhar de Samu: - "O Ibama cercou o Herculano e agora ele não canta mais!" - analisou o vaqueiro. Após os gestores do parque advertirem Herculano sem sucesso sobre sua atitude 
irregular, em maio de 2009, um mutirão foi realizado pela brigada contra incêndios do Ibama ${ }^{22}$ e em menos de um mês Herculano deparou-se com sua propriedade com fechos. O medo tomou conta das prosas desenroladas na varanda da casa de Samu. — "Se cercar, já manda nós embora!" — dizia dona Ló, ao pensar que o Ibama teria a mesma atitude com sua propriedade. Samu, por sua vez, proferia: - "Dá para viver, mas fica ruim para a criação, porque só tem o carrasco na terra".

O vaqueiro expressava, num primeiro momento, apenas sua preocupação com a reprodução da criação, onde ela comeria e beberia, já que pasto ele sabia que não poderia formar. No carrasco a criação conseguiria pastar apenas no 'tempo das águas'. Como seria 'na seca'? Enredado a isso, o medo de 'viver cercado' afligia aqueles sertanejos que sempre tiveram sua propriedade 'liberada'. Um 'dizer dos antigos' foi acionado por Zezão, sobrinho de Samu: - "Vó dizia que ia vir um tempo que homem ia andar pelo ar, carro ia andar sem boi e o mundo cercado por espinho". O 'Gerais', composto por pasto sem fecho, quintal sem cerca, gado criado 'na solta' e carro puxado por boi, era consumido por um 'Sertão' que fez o 'viver folgado' vestir vestes apertadas. O 'Sertão' criado pelo Ibama imprimiu uma nova ordem social, desenhada pela ausência de roçados, cercas na propriedade, sobrevoos de helicóptero, carros a gasolina andando daqui para acolá, além de proibições sobre o uso da terra, da fauna e da flora.

O órgão governamental justificou o cercamento de Herculano dizendo que ele estava utilizando muitos hectares fora dos limites de sua propriedade e que já não adiantava autuá-lo. Ademais, um proprietário de terras que também não recebeu a indenização pelos seus 25 mil hectares telefonou para o Ibama denunciando que alguém estava criando gado em sua propriedade - formada por glebas descontínuas - sem sua autorização. Com essa denúncia, eximia-se de multa ambiental por atividade irregular. Esse mesmo proprietário já havia deixado um documento no ano de 2000, no qual desautorizava a criação de gado em suas terras, como também a presença de posseiros, pois o último agregado que teve - Porcílio - botou fogo em 5.000 hectares para formar pasto. Após esse feito, o proprietário exigiu que Porcílio saísse e firmou esse documento.

A intenção do proprietário com esse escrito era expressar que não teria nenhuma responsabilidade se o contrário viesse a acontecer, o que se configuraria em falta de fiscalização do Ibama e não em infração ambiental por parte do primeiro. Em relação à denúncia mais recente, os gestores do parque concluíram que, além de Herculano, estavam utilizando a área o 'povo do Rio Preto' — Samu, Zezão e Raimundo - e o 'povo do Santa Rita' — os 'Paçoca', moradores distantes de Samu. 
O uso da área como pastagem para o gado, e que agora é parque, não é recente. Grande parte dessa área, que outrora se configurava como de uso comum, era utilizada pelos agregados das fazendas de gado do 'tempo dos Carneiro' para criarem seu gado 'na solta'. ${ }^{23}$ Com a 'chegada do parque', proibidos de usar a terra por não possuírem escritura, eles foram reassentados no Assentamento São Francisco, como dito anteriormente. No entanto, a maioria não havia recebido até aquele momento a indenização pelas benfeitorias que existiam em suas posses. Com isso, sentiam-se no direito de continuar a usar a área do parque como pastagem para seu gado, isto é, de usufruir das áreas de uso comum que utilizavam quando possuíam o 'direito de morar'. O 'povo dos Buracos', por sua vez, que mora no Vão dos Buracos ${ }^{24}$ - um espaço com uma geografia semelhante a um cânion - 'na seca', com o carrasco sem muito a oferecer para o gado, alugava pastos em propriedades ainda não indenizadas no interior do parque nacional (Cerqueira 2010).

O leitor pode estar se perguntando por que motivo a presença do gado não é admitida no parque. De acordo com os gestores, a justificativa apoia-se na legislação ambiental, principalmente no Sistema Nacional de Unidades de Conservação da Natureza (SNUC), ${ }^{25}$ bem como nas consequências da presença do animal doméstico para as relações ecológicas existentes no bioma cerrado. ${ }^{26}$

Pautados nessas justificativas, e diante do alvoroço que se formou com o cercamento da propriedade do Herculano, os gestores decidiram fazer uma reunião com a presença dos criadores de gado e da promotoria ambiental. Nessa reunião, ocorrida em agosto de 2009, o promotor explicou que criar gado em unidade de conservação era proibido, porque a legislação ambiental é bastante restritiva. Apoiou sua justificativa, sobretudo, no impacto ambiental que o gado causa sobre o ambiente. ${ }^{27}$ Ressaltou que a falta de indenização por suas propriedades e posses não lhes dava o direito de usar outras propriedades, tampouco de degradar o meio ambiente. Advertiu que, caso os criadores de gado utilizassem como pastagem áreas de terceiros, poderiam ser denunciados ao Ministério Público, tanto pelo proprietário da terra utilizada quanto pelo Ibama. Ademais, o promotor explicou que o uso indevido da área de terceiros poderia se configurar como esbulho possessório, ${ }^{28}$ sob pena de apreensão e possível perdimento das reses. A partir daquele momento, quem ainda não recebera a indenização por suas terras não poderia criar gado para além de sua propriedade; deveria cercar sua terra, bem como as áreas de veredas e vazantes de rios nela contidas, cujo ônus pelo cercamento seria do proprietário.

Durante essa reunião com o promotor, a gestora do parque informou aos criadores de gado que eles seriam indenizados até novembro de 2009; 
poderiam aguardar e retirar o gado quando tivessem recebido o pagamento e comprado outra terra. A partir dessa reunião, Samu e seus vizinhos nomearam a proibição de criar gado da forma como faziam no 'Gerais' do 'tempo dos Carneiro' como 'lei do promotor'. Neste cenário, o uso combinado das áreas de uso comum com as áreas de 'direito' foi desconsiderado. Esse sistema de uso combinado que vigorava quando ali era o 'Gerais' - e que fazia dele um território de reciprocidade, pautado numa moral camponesa - foi subsumido por leis ambientais sobre o uso da terra. ${ }^{29}$

Diante dessa nova lei sobre o uso da terra, Samu não teria como criar 800 reses em 150 hectares de terra, ressalvando as áreas de vereda e vazantes de rio. A solução encontrada pelo vaqueiro foi retirar o gado dos filhos, sobrinhos, netos e cunhados e levar parte dele para 'a Carinhanha', na fazenda onde um de seus filhos trabalhava, e outra parte para o Sítio do Abadia, onde outro filho estava ainda formando pasto. Quanto às suas 110 reses, Samu, num primeiro momento, tentou uma negociação com a gestora do parque.

Na sala principal do pequeno escritório do Ibama, com suas paredes trincadas e repletas de cartazes sobre cerrado, fauna, flora, além de um mural com fotos sobre o parque, onde seres humanos e não humanos dividem o espaço, Samu iniciou o assunto. - "Chegou novembro e nada de pagamento, né". Com a cabeça, a gestora confirmou a afirmação e respondeu: "É, Brasília é assim!" - "A senhora falou que podia esperar. Mas já tirei o gado. Quase tudo". Era novembro, e o pagamento pela indenização da terra não saíra até aquele momento. Samu queria então saber se poderia deixar por mais tempo só o gado dele, porque não iria — " "...] alugar pasto para pôr bezerros. [A] venda [dos bezerros] não dá dinheiro para pagar aluguel. Para recriar, fica caro por causa do aluguel" - explicou Samu à gestora. Além deste motivo, o vaqueiro tinha um alto gasto com os documentos exigidos para o processo de indenização. A gestora concordou que Samu mantivesse seu gado, mas sob algumas condições: como as áreas de Samu e de seu irmão Hermínio são contíguas e terminam no rio Carinhanha, deveria cercá-las no limite com o vizinho (que antigamente era o Dr. Luciano, para quem o ex-patrão de Samu vendera as terras) e, em suas áreas, cercar as veredas, conforme exigência do Código Florestal e da 'lei do promotor'.

Em relação ao vizinho, a gestora explicou que o atual proprietário deixara há anos um documento com o chefe anterior, no qual proibia a criação de gado em sua área e transferia a responsabilidade ao Ibama para que isso não ocorresse, como falado anteriormente. Ela mesma não teve contato com esse documento mas, como sabia de sua existência, deveria fazer cumprir o estipulado. Samu, de forma branda, reagiu e explicou à gestora que, se cercasse o vizinho e a vereda, ele poderia sair porque não teria como criar - 
"Onde gado vai comer e beber?" Além deste questionamento, Samu retomou seu relacionamento de outrora, o 'direito de criar' conquistado quando ainda trabalhava para a Família Carneiro. A gestora replicou afirmando: - "Isso foi antes do documento. Nunca vi esse documento, seu Samu, mas tenho que fazer cumprir!".

O vaqueiro reagiu ainda justificando que se cercasse somente o vizinho - "fica[va] apertado, mas da[va] pra viver". Por outro lado, cercando a vereda e o vizinho - " "pode me mandar embora, porque não dá pra viver, criar". Para reforçar sua argumentação, Samu trouxe à tona ainda o fato de não mais fazer roçado: - "Já vivo do compra. Se for para viver sem gado, daí posso morrer porque só sei viver onde gado está". Uma última questão se somava à indignação de Samu: para cercar o vizinho e a vereda teria que gastar mais dinheiro na terra; teria que comprar arame e mourões. Na sua lógica, não fazia sentido aplicar mais dinheiro numa terra que é sua, mas sobre a qual não possuía autonomia de uso, além de não saber quanto tempo mais teria que aguardar pela indenização. Para administrar essa situação, a gestora concordou que Samu criasse o gado na vereda ${ }^{30}$ e aceitou que usasse os 'paus' do mato como mourões, alternativa proposta por Samu. Dessa forma, gastaria somente com arame. Em julho de 2010, Samu contou que havia desistido de manter seu gado, que deixara apenas algumas reses 'para não perder o costume', vendera outras e oferecera outras à meia para um criador de gado.

A despeito desse cenário, o vaqueiro afirmava que não tinha o que reclamar do Ibama.

— Só falo só por conta que eles não pagam a gente para a gente sair caçando rumo para fazer plantio, como a gente tinha costume. É só o que eu falo. E é a criação que eles não querem que a gente crie. [...] "Então, paga a gente logo que a gente sai". Porque a criação tem que estar mais o dono! A gente ficar aí e a criação esparramar ou vender a criação para ficar no lugar não é vantagem. Antes a gente sair.

Samu propôs para vários gestores que passaram pelo Ibama trocar terra por terra.

— Eu digo: "Olha, vamos fazer um negócio que acho que fica bom para vocês. Vocês estão queixando que não têm dinheiro e isso e aquilo, que vai arrumar dinheiro... Nós fazemos trato. Vocês já mediram a minha [terra] aqui, sabe o tanto. Vocês me dão o mesmo tanto no outro canto. Mas assim, de eu mesmo escolher meu lugar! Porque vocês vão, escolhem um lugar com pouco não me 
serve. Eu escolhendo um lugar que me servir, aí eu falo para vocês, vocês vão, só pagam, passam a escritura no meu nome, entrego a escritura da de cá, e vocês me dão a outra".

A resposta que recebeu tanto dos gestores anteriores, quanto dos atuais foi: vamos ver se é possível. — "Acabou eles não viram... nada! [...] Indeniza e a gente fica na liberdade como era de princípio. Agora eu não tô liberto, porque tem que cumprir ordem, tem que pedir, procurar ordem".

O vaqueiro tem ciência que é monitorado, da mesma forma que a fauna - as onças pintadas, por exemplo - é monitorada pelos biólogos, para fazer um trocadilho ácido. Como narrou, sabe que, se não tivesse cumprido o determinado pelo órgão ambiental, teria sido, por exemplo, multado ou até deixaria de receber autorizações. Tem ciência de que, enquanto tiver que esperar pela indenização da terra, terá que 'atender às leis' para conseguir manter-se em sua terra, a despeito das dificuldades, como o 'viver do compra'. Por serem ele e sua esposa aposentados rurais, ele tem a possibilidade de acatar as 'ordens do Ibama', como, por exemplo, deixar de fazer o roçado. Seus vizinhos, por sua vez, não sendo aposentados, burlam as 'leis do Ibama'. Alguns, no dizer de Samu, 'fazem pirraça'. O vaqueiro narrou com sutileza, como é de seu feitio, outra situação que espelha a diferença de suas atitudes em comparação com a dos vizinhos.

- Também não dou direito para eles. Fazer coisa contra eles eu não faço! Se eu quero fazer uma coisa, eu vou lá e falo: “Ó, estou precisando disso aqui assim, assim, assim". Outra vez pedi [a] eles uma sucupira para botar eixo no carro [de boi]. "Êh, como é que faz?". Eu digo: "Ué, se faz é você me ceder a madeira para eu pôr eixo no meu carro..." Ela riu! Mas é porque tinha uns que já pirraçou ela demais e estavam lá... ela não queria dar! Aí ela deu sinal para mim. Aí ela tornou: "Ó, madeira seca não presta não?". Digo: "Presta não. Só verde". "É, está danado. Como é que nós fazemos?". Eu estava saindo e ela: “Ó, você pode tirar sua madeira. Onde você vir uns paus derrubados lá na barra do rio Preto, que lá eu já sei. Pode tirar". Mas eu não faço! Eu chegar, eu preciso e meter o machado, derrubar, tirar... sem pedir. Mesmo na terra da gente, mas a gente tem... que respeitar as leis.

Nessa cena, Samu referia-se a Raimundo e Róso como aqueles que faziam 'pirraça'. O vaqueiro diferenciava-se deles na forma de agir, isto é, ao atender 'às leis do Ibama', ao ser leal, muito embora explicitasse sua autonomia moral ao falar o que necessitava e como o Ibama poderia resolver sua questão. Nesse sentido, eram revelados conflitos em que diferentes 
sistemas morais eram ativados, às vezes por pessoas da mesma rede familiar, caso de Samu e Róso, em um contexto que envolvia, de um lado, as relações com parentes e, de outro, as relações com pessoas de fora, por exemplo, com o 'povo do Ibama'. ${ }^{31}$

No que se refere ao fato de sair da terra, Samu e seu irmão Hermínio, que adquiriram terras juntos e para isto fizeram uma única escritura, foram obrigados a fazer uma escritura para cada terra, pois isto se fazia necessário para abrir o processo amigável para receberem a indenização do Ibama. No entanto, o valor da irmandade prevalecia no pensamento de Samu no momento de saírem da terra, reafirmando a moral camponesa. Hermínio, viúvo há alguns anos e morando em Formoso-MG, deixou a cargo dos filhos os trâmites com o órgão governamental sobre o pagamento da indenização. Os filhos, por sua vez, não apresentavam entendimento: alguns se negavam a gastar além do que já haviam gasto até aquele momento para receberem pela terra. Zezão, o filho que cuidava da propriedade do pai, financeiramente não conseguia arcar sozinho com os custos. Samu, por ser padrinho, tio e, antes, irmão, se dispôs a custear os gastos porque - "quero que meu irmão saia junto comigo". O sair da terra e o entrar deveriam ocorrer no mesmo momento, porque são 'irmãos mesmo'. A terra é um patrimônio familiar, não somente como o local do trabalho, mas como patrimônio sobre o qual se construía a família enquanto valor. Assim, a terra para Samu não era mercadoria, e novamente os valores da moral camponesa reafirmavam-se.

Em 2011, Samu adoeceu. Com isso, por insistência dos filhos, foi com dona Ló para o Sítio do Abadia, região próxima a Formoso-MG, viver nas terras do filho mais velho, Santo. Por ali, campeando gado com o filho, aguarda pela indenização.

\section{Considerações finais}

No momento atual, quando a terra se configura como parque, a ambiguidade que vigora na relação de Samu com o patrão é transportada para sua relação com os gestores do parque. Na relação entre o vaqueiro e o 'povo do Ibama', destreza e agilidade são necessárias para saber como agir diante do inesperado: os gestores, que de tempos em tempos aparecem, ora sob a forma de homem, ora sob a forma de mulher, trazem com eles proibições sobre o uso da terra. O 'povo do Ibama' ou 'povo de Brasília', na verdade, se constitui como ser imprevisível que vai se transformando, ora é homem, ora é mulher, ora age de um jeito, ora de outro, às vezes a lei é uma, ora outra instrução normativa é sancionada. Não é como antes, quando a regra era 
uma só, quando vaqueiro e fazendeiro partilhavam da mesma ordem moral, o que os tornava iguais em honra.

No dizer de Raimundo, vizinho de Samu, que também partilha esta opinião - 'Lei vem é de trote. Não dá para andar manso'. O trote que alguém está armando ou o trote do cavalo que vem ligeiro. Não dá para andar devagar ou não dá para não ser valente, para se rebaixar: frase que ilustra a ambiguidade vivenciada na relação entre Samu e o povo do Ibama, agora que o Gerais é Sertão.

Pelo parque já passaram muitos gestores. Cada um com uma forma de agir perante o povo do Gerais. A lei que vem de trote afrouxa ou aperta de acordo com o pensar de quem manda e com o agir de quem espera pela indenização da terra.

Retomo a contribuição de James C. Scott para a análise que aqui faço sobre a relação do vaqueiro com o patrão e, posteriormente, com os gestores do parque nacional. No livro The moral economy of the peasant, Scott (1976) parte da noção de economia moral cunhada por E. P. Thompson (1998 [1991]), agregando a ela outros elementos ${ }^{32}$ ao estudar os camponeses asiáticos. Sua noção de economia moral considera que a ética de subsistência e o senso de justiça destacados na análise de Thompson permeiam, sobretudo, as relações recíprocas entre camponeses e senhores. A noção de economia moral de Scott inclui reciprocidades e trocas comunitárias, laços de dependência, obrigações mútuas, deveres e direitos sociais, senso de justiça, ética de subsistência, dentre outros elementos, sobretudo no que se refere às relações de poder no cotidiano. Dito de outro modo, segundo o autor, há uma moral entre camponeses e senhores, garantida tanto por direitos tradicionais quanto por laços pessoais, que atribui aos mais ricos a obrigação de minimizar o sofrimento e a exploração dos mais pobres. A violação ou o rompimento dessa moral pode gerar rebeliões por parte dos camponeses contra os senhores. Ou seja, a fim de defender seus interesses, os camponeses pautam-se nessa economia moral como uma estratégia de resistência contra a dominação dos senhores.

Essa leitura nos fornece pistas para compreender a relação de reciprocidade esperada por Samu, tanto na sua relação de outrora com seu patrão quanto na atual com o 'povo do Ibama'. Três aspectos alicerçavam a relação do 'tempo dos Carneiro' que, como falado anteriormente, foi transferida para a relação do vaqueiro com o 'povo do Ibama' como forma de resistência para Samu se manter junto a terra. O primeiro é a lealdade ao patrão. O segundo, que diz respeito especificamente ao modo de trabalho do vaqueiro a longo prazo, é a reciprocidade esperada por ele em função de sua lealdade, vislumbrada a partir do direito de poder acumular gado como contrapartida à sua lealdade e à sua honestidade. Um terceiro aspecto está em jogo nessa visão 
de reciprocidade a longo prazo: espera-se do patrão o respeito à dignidade do vaqueiro, fato que justifica, portanto, sua insubordinação. Este último ponto é bem destacado na análise de Scott (1976), muito embora em outro contexto, o de agricultores.

Como já colocado, a economia moral dos camponeses pressupõe que todos tenham acesso a certas condições mínimas de vida, abaixo das quais a rebelião se justifica. Especificamente no caso do vaqueiro, também se pressupõe uma trajetória que torne possível a autonomia, mas por meio da acumulação de gado.

Nessa esteira, a sensação de liberdade que Samu sentia quando trabalhava como vaqueiro encerrava-se na lida com o gado, bem como na possibilidade de acumular bens e na independência em relação ao mercado, já que outrora também tinha que solicitar permissão para o patrão. Atualmente, essa sensação de liberto se esvaiu por não poder acumular como dantes, porque o mexer com criação está restrito e por ter que 'viver do compra'. Um componente a mais está em jogo: Samu é proprietário de terra, muito embora não possa nela trabalhar.

Ao longo deste artigo, procurei mostrar que o 'Sertão' estava atravessado por tempos que se cruzavam: o 'tempo dos Carneiro' apresentava pontos de interseção com o tempo do 'viver apertado', do 'viver do compra'. Em ambos os tempos a vida era regrada. Contudo, ainda que Samu afirmasse seu respeito às regras, transportando para o momento atual o modelo de relação que desenvolvera enquanto vaqueiro com seu patrão - e a partir disso, buscasse se diferenciar — no tempo 'de primeiro' a troca de favores assegurava a ambas as partes - fazendeiro e vaqueiro - que nenhuma era subordinada à outra, principalmente devido à autonomia moral do vaqueiro. Valores e crenças eram compartilhados e asseguravam a coesão social. No presente, ainda que haja espaço para a negociação, para a reciprocidade, para a troca de favores, há, entretanto, um deslocamento da regra para a lei. Se a lei iguala todos os homens, Samu parece viver este princípio de igualdade como uma subordinação, pois agora as negociações e as trocas são feitas com a instituição; com isso a assimetria vez por outra se repõe.

Recebido em 16 de fevereiro de 2013

Aprovado em 20 de março de 2014

Carmen Silvia Andriolli é bolsista de pós-doutorado júnior CNPq do PPGAS/ MN/UFRJ. E-mail: <carmen.andriolli@gmail.com> 


\section{Notas}

* Uma primeira versão deste artigo foi apresentada no $35^{\circ}$ Encontro Anual da Anpocs em Caxambu, 2011. Agradeço ao CNPq pelo financiamento da pesquisa. Agradeço, sobretudo, aos pareceristas anônimos da Revista Mana e à Graziele Dainese pelas valiosas contribuições, que foram fundamentais para a versão final deste artigo.

${ }^{1}$ Cf. Sistema Nacional de Unidades de Conservação da Natureza - SNUC (Lei $\left.n^{\circ} 9985 / 2000\right)$.

${ }^{2}$ Refiro-me aqui à noção de habitus de Pierre Bourdieu. "Uma das funções da noção de habitus é a de dar conta da unidade de estilo que vincula as práticas e os bens de um agente singular ou de uma classe de agentes [...]. O habitus é esse princípio gerador e unificador que retraduz as características intrínsecas e relacionais de uma posição em um estilo de vida unívoco, isto é, em um conjunto unívoco de escolhas de pessoas, de bens, de práticas" (Bourdieu 1996 [1994]:21-22).

${ }^{3}$ Sobre as marcações textuais, informo que as aspas simples são usadas para marcar forma nativa de falar. Por exemplo: 'Gerais'. Travessão seguido por "aspas duplas": para marcar frase exata dita pelo vaqueiro e/ou vizinhos e registrada em diário de campo. Por exemplo: - "Entra para dentro, compadre".

${ }^{4}$ Sobre outros estudos dedicados à análise do sentido local do tempo em diferentes universos empíricos, ver: Palmeira e Heredia (1997); Evans Pritchard (2007 [1940]); Borges (2003); Medeiros (2011).

${ }^{5}$ Em Os Nuer, Evans Pritchard (2007 [1940]) trabalha em conjunto as categorias "tempo" e "espaço", forma bastante inspiradora para a análise que faço aqui. No entanto, por limite de espaço, não estabelecerei aproximações e/ou afastamentos com sua análise. A despeito disso, penso ser importante deixar registrada a conclusão do autor sobre o tempo para os Nuer: "Eles pensam [o tempo] com muito maior facilidade em função das atividades e de sucessões de atividades e em função da estrutura social e das diferenças estruturais do que em unidades puras de tempo" (:116).

${ }^{6}$ Refiro-me aqui à noção de estrutura da conjuntura elaborada por Sahlins (2011 [1985]): “[...] Estrutura da conjuntura: um conjunto de relações históricas que, enquanto reproduzem as categorias culturais, lhes dão novos valores retirados do contexto pragmático" (:156).

${ }^{7}$ Definida pelo autor como "constitutiva de uma ordem moral, isto é, de uma forma de perceber as relações dos homens entre si e com as coisas, notadamente, a terra" (Woortmann 1990 [1987]:11).

${ }^{8}$ Isto é, o amor à "mãe-terra" que é um tropo na literatura sobre campesinato russo, por exemplo, e também no campesinato latino-americano e, de modo mais 
geral, presente na noção de "território tradicionalmente ocupado" em que se subentende uma ligação profunda e íntima de pessoas com um território que é único, é aquele e não é outro.

${ }^{9}$ Nos trabalhos de Dayrell (1998); Nogueira (2009); Ribeiro (2010) e Correia (2002), o Gerais do Norte e o Noroeste do Estado de Minas Gerais compunham-se por um sistema de uso da terra que combinava áreas de uso comum e áreas de chapadas, tabuleiros, campinas, campos, vazantes e vargens (conforme a nomenclatura regional empregada) - utilizadas, segundo os autores, para a solta do gado e para o extrativismo - em simbiose com a ocupação e o uso, por unidade doméstica, de áreas à beira de corpos d'água - veredas, riachos, terras de cultura. Tanto as terras devolutas quanto as de grandes fazendas eram ocupadas pelos camponeses, época em que o direito sobre elas legitimava-se pelo uso. As áreas de uso comum, de acordo com Ribeiro, 2010, eram terras de domínios definidos nos direitos de herança, entretanto usufruídas sem divisas, conforme o regime denominado "compáscuo" no antigo direito português e brasileiro. O uso combinado das áreas de uso comum com as áreas de direito pouco alterou a dinâmica e a estrutura dos ecossistemas predominantes, bem como garantiu a produção e a reprodução camponesa, que estavam atreladas ao conjunto e ao fluxo de recursos e não ao controle da terra.

${ }^{10}$ Cf. Almeida (1979); Galvão (1972); Capistrano de Abreu (s/d).

${ }^{11}$ Outras acepções para vazantes, vargens, chapadas, tabuleiro, gerais, ver em Nogueira (2009) e Ribeiro (2010).

${ }^{12}$ Sobre outros sistemas de uso combinado sobre a terra e recursos naturais, ver, por exemplo, Godoi (1998) e Almeida (2009).

${ }^{13}$ Cf. Correia (2002). Em sua pesquisa de campo, o autor encontrou ainda a categoria nativa "terras de ausentes" como referência às terras legalmente consideradas como devolutas.

${ }^{14}$ Sobre as relações cotidianas entre vaqueiro e patrão, ver Ribeiro (2010b) e Medrado (2012).

${ }^{15}$ Ver Galvão (1972:32-33) sobre posse de cavalo e a sensação de liberdade que seu uso proporciona ao trabalhador, diferenciando-o do trabalhador que labuta no cabo da enxada, no chão, num espaço restrito, sem muito circular. Ver ainda sobre a posse de gado recebido por meio da quarta, conferindo ao trabalhador a possibilidade de passar de empregado a dono.

${ }^{16}$ Com a implantação do parque nacional, Samu será desapropriado, assim como os demais proprietários de terra escriturada. Receberá uma indenização tanto pela terra quanto pelas benfeitorias nela existentes. O processo indenizatório está em curso há mais de sete anos. Samu afirma que, enquanto não receber a indenização, não abandona a terra. 
${ }^{17}$ A literatura de cordel possui folhetos que narram como essa lealdade do vaqueiro ao seu patrão foi colocada à prova pelo próprio patrão, como, por exemplo, no cordel "História do Boi Leitão ou O Vaqueiro que não mentia", de Francisco Firmino de Paula.

${ }^{18}$ Cf. Almeida (1979). Em sua análise sobre a literatura de cordel, o autor mostra que nestas histórias a posição de vaqueiro era vista como parte de um ciclo, e não como estática. Vaqueiros leais e valentes podiam tornar-se fazendeiros, ao acumular gado; esse ideal era expresso nas narrativas como o casamento do vaqueiro com a filha do patrão, isto é, não como uma ruptura com o sistema de fazendas, mas como uma transição no ciclo doméstico consumada com o casamento.

${ }^{19}$ A literatura de cordel já retratara essa ambiguidade. Por exemplo, na "História do boi misterioso" de Leandro Gomes de Barros, uma história baseada em antigos romances de boi. Ela é atravessada pelo componente mistério, que pode ser visto como uma propriedade da natureza por oposição à fazenda dominada pelo homem. O mistério escapa ao controle do fazendeiro proprietário, está associado à natureza, especificamente ao boi avesso ao domínio do fazendeiro. Anteriormente à literatura de cordel, José de Alencar, ao narrar os romances de boi, mencionou os gados selvagens, que deveriam ser eliminados para não desencaminharem o gado manso. Essa afirmação traz a ambiguidade, na medida em que o próprio gado doméstico é meio selvagem. Na história do boi misterioso, a ambiguidade revela-se pelo mistério: o boi realmente é encantado? Quem o marcou? Como ele se metamorfoseia numa águia ao passo que transforma o vaqueiro, que tinha um pacto com o diabo, e seu cavalo em corvos? O fazendeiro, diante de seu fracasso, vende todas as suas fazendas, bem como deixa de criar gado. O poder do fazendeiro mostra-se, assim, limitado por uma instância sagrada, à qual pertence o boi (Almeida 1979). Palmeira (2009 [1977]), ao analisar as transformações ocorridas na plantation canavieira do nordeste brasileiro no que tange às relações sociais, explorou a ambiguidade que perpassava o acesso ao sítio (isto é, qual morador tinha a possibilidade de recebê-lo, onde se localizava), bem como os significados de sua concessão, tanto para o morador quanto para o senhor de engenho.

${ }^{20}$ Zezão e um dos filhos de Hermínio, irmão de Samu. Este sofreu um derrame há alguns anos, fato que o obrigou a se mudar para o município de Formoso-MG. Zezão mudou-se com a família para a casa que era do pai, com sua esposa Elena e duas filhas. Samu conta que antes do sobrinho Zezão mudar-se para lá ficava meses sem ver, sem conversar com ninguém por não haver outros moradores naquelas bandas devido à 'chegada do parque'.

${ }^{21}$ Medeiros (2011) analisou as transformações sobre o tempo e o espaço percebidas pelos posseiros que foram realocados para o Assentamento São Francisco. Sobre as consequências desse reassentamento, ver Medeiros (2011).

${ }^{22}$ Vinculada ao PrevFogo (Centro Nacional de Prevenção e Combate aos Incêndios Florestais). Em: http://www.ibama.gov.br/prevfogo/ 
${ }^{23}$ Cf. descrito também nos trabalhos de Jacinto (1998) e Correia (2002).

${ }^{24}$ O Vão dos Buracos se localiza no rumo oposto ao do parque, numa distância de aproximadamente 50 quilômetros do início do parque, atravessando a área do município de Chapada Gaúcha.

${ }^{25}$ Cf. Artigo $2^{\circ}$, parágrafo IX do SNUC (Lei no $\left.9985 / 2000\right)$.

${ }^{26}$ No que tange às relações ecológicas, a justificativa para a não presença do gado pauta-se no que foi expresso por um dos gestores: porque o gado degrada o meio ambiente devido ao intenso pisoteio e por espantar a fauna silvestre. Além disso, atrapalha a pesquisa; e se campearem gado com cachorro, um dos cachorros pode ser caçador. E aí?

${ }^{27}$ De acordo com o promotor, o número de cabeças de gado que o solo comporta de forma que não degrade o ambiente é de três cabeças/hectare. Isto não está em lei. O promotor baseou-se em "estudos técnicos".

${ }^{28}$ Cf. http://www.jusbrasil.com.br/topicos/289462/esbulho-possessorio: "Esbulho possessório: 1. Ato violento, em virtude do qual uma pessoa é despojada ou desapossada de um bem legítimo, caracterizando crime de usurpação. 2. Crime contra o patrimônio consistente em invadir terreno ou edifício alheio, com o intuito de adquirir a posse".

${ }^{29}$ Esse cenário nos remete ao estudo de Karl Marx (2007). Com a intensificação do processo de privatização da posse da terra, o uso por camponeses das lenhas caídas no chão passou a ser tratado como furto. Esse cenário de criminalização de um modo de vida foi analisado também por E. P. Thompson (1987 [1975]) em seu estudo sobre a Lei Negra na Inglaterra do século XVIII. Esta lei criminalizou as ações de caçadores que viviam nos arredores dos parques e das florestas oficiais. Esses caçadores reivindicavam seu direito costumeiro para continuar com seu modo de vida pautado na utilização da floresta como área de uso comum, bem como no uso de cervos, galhos, lenha, peixes. Por último, a 'lei do promotor' nos remete ainda para o estudo de Karl Polanyi (2000 [1944]) sobre a reação de camponeses, também na Inglaterra do século XVIII, ao processo de cercamento das terras, até então de uso comum, por mercadores.

${ }^{30}$ A gestora concordou informalmente, porque não poderia, por exemplo, firmar um documento, pois estaria infringindo o código florestal.

${ }^{31}$ Em Tipos de campesinato latino-americano, Eric Wolf (2003), ao diferenciar as comunidades corporadas fechadas das comunidades abertas traz à tona os diferentes sistemas morais que regiam uma e outra no que tange às relações com pessoas de fora da comunidade, sobretudo em relação à venda da terra.

${ }^{32}$ E. P. Thompson (1998 [1991]) dedicou-se à análise das rebeliões das multidões inglesas no século XVIII, período em que dois modelos econômicos contrastavam-se: 
o paternalista e o da economia política de livre mercado. Nesse cenário, os pobres ingleses - a multidão - diante do presente que lhes era apresentado, reelaboravam as noções do velho modelo, cuja base estava apoiada em certos costumes e leis, como forma de garantirem sua subsistência. Em outras palavras, por meio de pressupostos éticos e morais, alicerçados em costumes, na tradição e em um consenso popular, os pobres cobravam dos fazendeiros e dos comerciantes ricos preços justos para os alimentos em períodos de crise que, ao serem desrespeitados, produziam indignações e ações diretas como forma de controlar os preços dos alimentos.

\section{Referências bibliográficas}

ALMEIDA, Alfredo Wagner Berno de. 2009.

"Terras de preto, terras de santo, terras de índio: uso comum e conflito". In: E. P. Godoi; M. A. Menezes \& R. A. Marin (orgs.), Diversidade do campesinato: expressões e categorias. Vol. II: Estratégias de reprodução social. Coleção História Social do Campesinato Brasileiro. São Paulo/ Brasília: EdUnesp/ Nead. pp. 39-66.

ALMEIDA, Mauro William Barbosa. 1979. Folhetos. A literatura de cordel no NE Brasileiro. Dissertação de Mestrado, Faculdade de Filosofia, Letras e Ciências Humanas, Universidade de São Paulo, São Paulo. 2 vols.

ANDRIOLLI, Carmen Silvia. 2011. Sob as vestes de Sertão Veredas, o Gerais: "Mexer com criação" no Sertão do IBAMA. Tese de Doutorado, Programa de Pós-Graduação em Ciências Sociais, Campinas/SP, Universidade Estadual de Campinas.

BARROS, Leandro Gomes de. s/d. História do boi misterioso. São Paulo: Luzeiro Editora Ltda.

BENJAMIN, Walter. 1996 [1975]. "O narrador. Considerações sobre a obra de Nikolai Leskov". In: Magia e técnica, arte e política: ensaios sobre a literatura e história da cultura. (Walter Benjamin, Obras escolhidas, vol. 1) São Paulo: Brasiliense. pp. 197-221. BORGES, Antonádia. 2003. Tempo de Brasília: etnografando lugares-eventos da política. Rio de Janeiro: Relume Dumará/ Núcleo de Antropologia da Política-UFRJ.

BOURDIEU, Pierre. 1996 [1994]. Razões práticas. Sobre a teoria da ação. Campinas: Papirus.

CÂMARA CASCUDO, Luiz da. 1972. Dicionário do folclore brasileiro. Brasília: Instituto Nacional do Livro, Ministério da Educação e Cultura. - 1984. Vaqueiros e cantadores. Belo Horizonte/ São Paulo: Ed. Itatiaia/ Edusp.

CAPISTRANO DE ABREU, João. s/d. Capítulos de história colonial. Brasília: Ministério da Cultura, Fundação Biblioteca Nacional, Departamento Nacional do Livro. Disponível em: http://www.dominiopublico.gov.br/ download/texto/bn 000062.pdf. Acesso em: 24/09/2010.

CERQUEIRA, Ana Carneiro. 2010. O "povo" parente dos Buracos: mexida de prosa 
e cozinha no cerrado mineiro. Tese de doutorado. Pós-Graduação em Antropologia Social. Rio de Janeiro, RJ: Universidade Federal do Rio de Janeiro, Museu Nacional.

CORREIA, Cloude de Souza. 2002. Do Carrancismo ao Parque Nacional Grande Sertão Veredas: (des)organização fundiária e territorialidades. Dissertação de mestrado. Pós-Graduação em Antropologia Social. Brasília, DF: Universidade de Brasília.

DAYRELL, Carlos Alberto. 1998. Geraizeiros e biodiversidade no norte de Minas: a contribuição da agroecologia e da etnoecologia nos estudos do agrossistemas tradicionais. Dissertação de mestrado. Maestria en Agroecologia y Desarollo Rural Sostenible. Santa Maria de La Rábida, Espanha: Universidad Internacional de Andalucia, Sede Ibero Americana.

EVANS-PRITCHARD, E. E. 2007 [1940]. Os Nuer: uma descrição do modo de subsistência e das instituições políticas de um povo nilota. São Paulo: Perspectiva.

FRANCO, Maria Sylvia de Carvalho. 1997. Homens livres na ordem escravocrata. $4^{\mathrm{a}}$. ed. São Paulo: EdUnesp. GALVÃO, Walnice Nogueira Galvão. 1972. As formas do falso. Um estudo sobre a ambiguidade no Grande Sertão: Veredas. São Paulo: Ed. Perspectiva. GODOI, Emília Pietrafesa de. 1998. "O sistema do lugar: história, território e memória no sertão". In: Ana Maria Niemeyer; Emília Pietrafesa de Godoi (orgs.), Além dos territórios: para um diálogo entre a etnologia indígena, os estudos rurais e os estudos urbanos. Campinas: Mercado das Letras. pp. 97-166.

JACINTO, A. B. M. 1998. Afluentes da memória: itinerários, taperas e histórias no Parque Nacional Grande Sertão Veredas. Dissertação de Mestrado, Pós-Graduação em Antropologia, Campinas-sp, Universidade Estadual de Campinas.
MARX, Karl. 2007. "Debates acerca da lei sobre o furto de madeira (1842)". Gazeta Renana 298. Tradução de Emil Asturig von München. Disponível em: http://www.scientific-socialism. de/KMFEDireitoCAP7Port.htm\#_ftn1. Acesso em: 10/10/2012.

MAUSS, Marcel. 2003 [1950]. "Ensaio sobre a dádiva. Forma e razão da troca nas sociedades arcaicas". In: Sociologia e antropologia. São Paulo: Cosac Naify. pp. 183-314.

MEDEIROS, C. 2011. No rastro de quem anda: comparações entre o "tempo do Parque" e o "hoje" em um assentamento no noroeste mineiro. Tese de Doutorado, Pós-Graduação em Antropologia Social, Museu Nacional/ UFRJ, Rio de Janeiro.

MEDRADO, Joana. 2012. Terra de vaqueiros: relações de trabalho e cultura política no sertão da Bahia, 1880-1900. Campinas: Ed. Unicamp.

MOURA, M. M. 1988. Os deserdados da terra. A lógica costumeira e judicial dos processos de expulsão e invasão da terra camponesa no sertão de Minas Gerais. Rio de Janeiro: Bertrand Brasil.

NOGUEIRA, M. 2009. Gerais a dentro e a fora: identidade e territorialidade entre Geraizeiros do Norte de Minas Gerais. Tese de Doutorado, Pós-Graduação em Antropologia Social, Universidade de Brasília, Brasília.

PALMEIRA, Moacir. 2009 [1977]. "Casa e trabalho: nota sobre as relações sociais na plantation tradicional". In: C. Welch et al. (orgs.), Camponeses brasileiros: leituras e interpretações clássicas. Vol. 1. São Paulo/ Brasília: EdUnesp/ Nead. pp. 203-215.

· 2001. "Política e tempo: nota exploratória". In: M. Peirano (org.), O dito e o feito: ensaio de antropologia dos rituais. Rio de Janeiro: Relume Dumará. pp.171-177. 
__; HEREDIA, Beatriz. 1997. "Política ambígua". In: P. Birman; R. Novaes \& S. Crespo (orgs.), O mal à brasileira. Rio de Janeiro: EdUERJ. pp.159-183. POLANYI, Karl. 2000 [1944]. A grande transformação: as origens da nossa época. Rio de Janeiro: Elsevier.

RIBEIRO, Eduardo Magalhães. 2010. "As histórias dos Gerais". In: Eduardo Magalhães Ribeiro (org.), Histórias dos Gerais. Belo Horizonte: Ed. UFMG. pp. 23-39.

- 2010b. "Agregados e fazendas no nordeste de Minas Gerais". Estudos Sociedade e Agricultura, 18(2):393-433. ROSA, Guimarães. 2001. Grande Sertão: Veredas. Rio de Janeiro: Nova Fronteira. - 2001. Sagarana. Rio de Janeiro: Nova Fronteira.

SAHLINS, Marshall. 2011 [1985]. Ilhas de história. Rio de Janeiro: Zahar.

SCOTT, J. 1976. The moral economy of the peasant: rebellion and subsistence in Southeast Asia. New Haven and London: Yale University Press.

- 1985. Weapons of the weak. Everyday forms of peasant resistence. New Haven: Yale University Press.

- 1990. Domination and the arts of resistance: hidden transcripts. New Haven: Yale University Press. . 2002. "Formas cotidianas da resistência camponesa". Raízes, 21(1):10-31.

THOMPSON, E. P. 1998 [1991]. "A economia moral da multidão inglesa no século XVIII". In: Costumes em comum. Estudos sobre a cultura popular tradicional. São Paulo: Companhia das Letras. pp. 150-202.

- 1987 [1975]. Senhores e caçadores: a origem da lei negra. Rio de Janeiro: Paz e Terra.

WOLF, Eric. 1976 [1966]. Sociedades camponesas. Rio de Janeiro: Zahar Editores. . 2003 [1955]. "Tipos de campesinato latino-americano: uma discussão preliminar". In: B. Feldman-Bianco \& G.
L. Ribeiro (orgs.), Antropologia e poder. Contribuições de Eric Wolf. Brasília/ São Paulo: Ed. UnB/ Imprensa Oficial/ Ed. Unicamp. pp. 117-144.

WOORTMANN, K. 1990 [1987]. "Com parente não se neguceia: o campesinato como ordem moral". Anuário Antropológico, 87:11-73. 


\section{Resumo}

O fulcro deste artigo é refletir sobre a dinâmica da relação entre o vaqueiro Samuel Borges dos Santos e os gestores do Parque Nacional Grande Sertão Veredas. O pano de fundo são as transformações nos usos da terra que compuseram o 'Gerais' em 'Sertão'. Meu objetivo é elucidar que o vaqueiro Samuel transportava o modelo de relação que desenvolvera com seu ex-patrão para sua relação com os gestores do parque enquanto esperava pela indenização de sua propriedade. Como forma de resistência, compreendida aqui como "arma dos fracos", o vaqueiro agiu desta forma durante 21 anos para se manter junto a terra, a despeito da legislação ambiental.

Palavras-chave Etnografia, Vaqueiro, Terra, Resistência, Tempo.

\section{Abstract}

The aim of this article is to reflect on the dynamics of the relationship between the herdsman Samuel Borges dos Santos and the managers of the National Park Grande Sertão Veredas. The background are the changes to land use that comprised the 'Gerais' in 'Sertão'. I argue that Samuel transposed the model of the relationship that he developed with his former employer to his relationship with the managers of the park while he waited for the indemnification of his property. As a form of resistance, understood here as a "weapon of the weak", the herdsman acted in this way for 21 years in order to remain in the land in the face of the determinations of environmental legislation. Key words Ethnography, Herdsman, Land, Resistance, Time. 